\title{
Cost-Effectiveness of Automated Telephone Self-Management Support With Nurse Care Management Among Patients With Diabetes
}

\author{
Margaret A. Handley, $P b D, M P H^{1,2,4}$ \\ Martha Shumway, $P b D^{3}$ \\ Dean Schillinger, $M D^{2,4}$ \\ ${ }^{1}$ Department of Epidemiology and Biosta- \\ tistics, Division of Preventive Medicine and \\ Public Health, University of California, San \\ Francisco, San Francisco General Hospital \\ ${ }^{2}$ Department of Medicine, University of \\ California, San Francisco, San Francisco \\ General Hospital
}

${ }^{3}$ Department of Psychiatry, University of California, San Francisco, San Francisco

General Hospital

${ }^{4}$ University of California, San Francisco, Center for Vulnerable Populations, San Francisco General Hospital

\begin{abstract}
PURPOSE This study evaluated the cost-effectiveness of an automated telephone self-management support with nurse care management (ATSM) intervention for patients with type 2 diabetes, which was tested among patients receiving primary care in publicly funded (safety net) clinics, focusing on non-English speakers.
\end{abstract}

METHODS We performed cost analyses in the context of a randomized trial among primary care patients comparing the effects of ATSM $(n=112)$ and usual care $(n=114)$ on diabetes-related outcomes in 4 San Francisco safety net clinics. ATSM uses interactive phone technology to provide surveillance, patient education, and one-on-one counseling, and was implemented in 3 languages for a 9month period. Cost utility was examined using quality-adjusted life-years (QALYs) derived from changes in scores on the 12-Item Short Form Health Survey. We also examined cost-effectiveness for costs associated with a $10 \%$ increase in the proportion of patients meeting diabetes-specific public health goals for increasing exercise, as recommended by Healthy People 2010 and the American Diabetes Association.

RESULTS The annual cost of the ATSM intervention per QALY gained, relative to usual care, was $\$ 65,167$ for start-up and ongoing implementation costs combined, and $\$ 32,333$ for ongoing implementation costs alone. In sensitivity analyses, costs per QALY ranged from $\$ 29,402$ to $\$ 72,407$. The per-patient cost to achieve a $10 \%$ increase in the proportion of intervention patients meeting American Diabetes Association exercise guidelines was estimated to be $\$ 558$ when all costs were considered and $\$ 277$ when only ongoing costs were considered.

CONCLUSIONS The ATSM intervention for diverse patients with diabetes had a cost utility for functional outcomes similar to that of many other accepted interventions targeted at diabetes prevention and treatment, and achieved public health physical activity objectives at modest costs. Because a considerable proportion of costs were fixed, cost-utility and cost-effectiveness estimates would likely be substantially improved in a scaled-up ATSM program.

Ann Fam Med 2008;6:512-518. DOI: 10.1370/afm.889.

\section{INTRODUCTION}

I $\mathrm{n}$ the United States, costs associated with chronic illness care account for nearly $75 \%$ of medical expenditures. ${ }^{1}$ Type 2 diabetes, which affects more than 20 million individuals in this country alone, is associated with substantial morbidity and cost. Although organ damage related to diabetes is well recognized, diabetes also causes functional decline, depression, pain, and lost productivity. ${ }^{2.5}$ The estimated direct and indirect societal and health system costs attributable to diabetes totaled approximately $\$ 132$ billion in 2002 , with costs expected to rise to $\$ 156$ billion by $2010 .^{6-8}$

In recent reviews of the cost-effectiveness of interventions for prevent- 
ing or treating diabetes in developed countries, the majority of studies focus either on screening for diabetes or on treatment to avert complications, emphasizing medication-sensitive outcomes with long-term benefits. 2,8,9 There are still many gaps in our knowledge regarding strategies aimed at improving diabetes outcomes, including whom they most benefit and at what costs. These gaps are especially pronounced with regard to understanding the impact of self-management support programs on functional outcomes, ${ }^{9}$ which represent an increasingly important component of the nonmortality burden associated with diabetes and diabetes-related comorbidities. ${ }^{10}$ In addition, few studies include individuals from racial and ethnic minorities and of lower socioeconomic status-populations disproportionately affected by diabetes. Finally, because self-management support interventions are increasingly being implemented using population-based health communication strategies, such as those using telephone or computer-assisted outreach with or without nurse care manangement, ${ }^{11}$ it is important to measure the value of these programs from a public health perspective with respect to desired changes in health behaviors.

We undertook a cost-related study of a health communication-based intervention that uses health information technology to support patients with type 2 diabetes in their self-management. Specifically, we compared the cost utility of automated telephone self-management support plus nurse care management (ATSM) with that of usual care among diverse patients with diabetes enrolled in a randomized trial. This trial demonstrated 1-year improvements in health behaviors and functional outcomes with ATSM relative to usual care, ${ }^{12,13}$ including health-related quality of life measures. The trial did not, however, demonstrate differences in metabolic outcomes (hemoglobin $\mathrm{A}_{1 \mathrm{c}}\left[\mathrm{HbA}_{1 \mathrm{c}}\right]$, blood pressure) or use of services (such as emergency services).

In this new analysis, we sought to answer the following cost-related research questions:

1. What is the cost utility of ATSM relative to usual care? We addressed this question by examining qualityadjusted life-years (QALYs) calculated from participant responses to the health status measure of the 12-Item Short Form Health Survey (SF-12).

2. What is the cost-effectiveness of ATSM with respect to meeting diabetes-specific public health goals? We addressed this question by estimating the costs of achieving a $10 \%$ increase in the proportion of individuals meeting public health goals consistent with Healthy People 2010 objectives regarding exercise, ${ }^{14}$ and getting amounts of exercise recommended by the American Diabetes Association for patients with diabetes. ${ }^{15,16}$

\section{METHODS Trial Overview}

We conducted a randomized controlled trial of selfmanagement support among diverse patients with diabetes in a safety net system that is part of a practice-based research network in the San Francisco Bay Area (the UCSF Collaborative Research Network). The IDEALL trial (Improving Diabetes Efforts Across Language and Literacy) has been previously described. ${ }^{12,13,17}$ In brief, 339 English-, Spanish-, and Cantonese-speaking primary care patients with diabetes in 4 safety net clinics from the San Francisco Department of Public Health's integrated delivery system (Community Health Network) were randomized to receive ATSM, group medical visits, or usual care for 9 months. The interventions were developed as adjuncts to usual care. Study variables were measured at baseline and 12 months, and focused on features of the Chronic Care Model, including structures and processes of care; behavioral outcomes (diabetes selfmanagement, exercise, and diet); metabolic outcomes $\left(\mathrm{HbA}_{\mathrm{cc}}\right.$ levels); and functional outcomes (number of bed-days and general health status as assessed with the SF-12). This last measure, the SF-12, is a multidimensional generic measure of patient-reported health status. ${ }^{18}$ The cost analysis reported here compared ATSM with usual care and did not include data from the group medical visits arm because this form of diabetes self-management was not associated with any improvements in functional status relative to usual care.

\section{ATSM Support}

ATSM uses interactive telephone technology to provide surveillance and patient education and, when combined with nurse care management in the form of one-on-one telephone counseling, has been demonstrated to improve satisfaction and functional status among patients with diabetes. ${ }^{19,20}$ ATSM is increasingly considered by health systems, including managed care health plans, ${ }^{21}$ to be a promising health information technology; of note, it can be tailored to a range of language and literacy levels, can provide health education, and can promote continuity of care without requiring patient travel or appointments. These features make ATSM particularly well suited for vulnerable populations who may have limited language and literacy skills and who may have comorbidities and other barriers to accessing health care that limit opportunities to obtain self-management support. ${ }^{13}$

\section{Trial Participants}

We identified trial participants by using a populationbased recruitment strategy and a diabetes registry developed for the Community Health Network. To be 
eligible, patients had to have the following characteristics: age older than 17 years, International Classification of Diseases Ninth Revision (ICD-9) codes consistent with type 2 diabetes, speaker of 1 of the 3 most common languages in the clinic system (English, Spanish, or Cantonese), at least 1 primary care visit in the preceding 12 months, at least 1 recorded $\mathrm{HbA}_{1 \mathrm{c}}$ value, and no psychotic illness or end-stage renal disease. Additionally, patients were required to have suboptimal glycemic control $\left(\mathrm{HbA}_{1 \mathrm{c}}\right.$ values $\left.\geq 8.0 \%\right)$. We recruited patients between June 2003 and December 2004. The trial was approved by the University of California, San Francisco, and the Community Health Network Institutional Review Boards.

\section{Quality-Adjusted Life-Years}

QALYs are a measure of health outcome that integrates quality and quantity of life into a common metric that reflects patient preferences and facilitates comparison across health conditions and interventions. QALYs are measured on a scale that ranges from 0 to 1 , where 0 corresponds to death and 1 corresponds to perfect health. ${ }^{8,22}$ In cost-utility analyses, costs are expressed in monetary units, but health benefits are expressed in QALYs. QALYs are increasingly used to measure the effectiveness of diabetes interventions. ${ }^{2,8}$ In this study, we focused on QALYs gained or lost over a 1-year period.

We calculated QALYs from SF-12 responses using established conversion procedures described by Brazier and Roberts ${ }^{23}$ that have been validated in other populations. ${ }^{10,24}$ That study provides model-based coefficients derived from standard gamble ratings of health states among a representative sample of UK residents. These coefficients are applied to individual SF-12 responses to calculate QALYs. For each participant, we calculated QALYs using baseline and 12-month SF-12 responses, and then computed the difference between the 2 values.

\section{Cost Measurements}

In this cost analysis, we used a health systems/program perspective, focusing on direct implementation costs. ${ }^{25-27}$ We calculated costs for ATSM only, as there were no additional costs associated with usual care (ATSM was an adjunct to this care), and because use of health care services did not differ between the 2 groups. Intervention costs included nurse care manager training; development of ATSM messages; translation and recording of messages in 3 languages; programming setup costs for ATSM; patient recruitment and follow-up time; fixed monthly ATSM maintenance; costs associated with outgoing weekly ATSM calls; and direct nurse telephone care management with patients. These costs were divided into start-up costs (eg, costs associated with setting up ATSM, staff training, and personnel time for developing messages and protocols) and ongoing implementation costs (eg, cost of the active nurse care management activities, patient recruitment and retention, and monthly ATSM service costs).

There were no transportation costs for ATSM. We did not include indirect costs of patient time, because the small amount of time (approximately 5 minutes) spent answering the weekly automated calls was unlikely to burden patients, and the time spent talking with the nurse care manager was perceived as a direct patient benefit. A 29\% institutional overhead charge was applied to personnel costs associated with ongoing ATSM. ${ }^{28}$ Because personnel and system costs did not change over the study period, we did not make any adjustments for inflation. Data sources included personnel income records, administrative databases, and charge-related reports from the ATSM system provider (Prosodie Inc, Calgary, Canada).

\section{Cost-Utility Analysis}

The cost-utility ratio indicates the cost to save 1 QALY relative to other interventions or care aimed at treating or preventing the same disease..$^{8,29}$ The numerator in the cost-utility ratio is the monetary cost of the ATSM intervention minus the monetary benefits. The denominator is the QALY gained by the intervention relative to the comparator (usual care). Combining the data on the difference in QALYs between the 2 study arms and the cost data, we estimated the cost associated with achieving an increase of 1 QALY in SF-12 score with ATSM, using the following equation:

Cost-utility ratio $=($ cost of ATSM $) /($ QALY for ATSM-QALY for usual care)

To help health system planners interpret the results, we also calculated the cost per QALY using start-up and ongoing costs combined (Model A) and using just the ongoing costs (Model B).

In addition, we performed a sensitivity analysis by examining the effects of a $10 \%$ variation in the QALY estimate in both directions (a 10\% increase and a 10\% decrease).

\section{Costs Associated With Increased Guideline Achievement}

We calculated the per-patient costs associated with achieving a $10 \%$ increase with ATSM relative to usual care in the proportion of patients achieving minimum standards for moderate or vigorous physical activity or exercise over the study period. A $10 \%$ increase was selected as a meaningful population health outcome as it is consistent with Healthy People 2010 Physical Activity and Fitness Objectives 22-2 to 22-6, which 
advocate for $10 \%$ to $15 \%$ increases relative to baseline levels. ${ }^{14}$ We used American Diabetes Association guidelines ${ }^{15,16}$ to obtain definitions of exercise most relevant to our trial population.

Based on these guidelines, we converted patient reports for physical activity duration (minutes) and frequency (times per week) into an estimate of the number of episodes per week of moderate or vigorous physical activity. We then estimated the proportion of patients who achieved 5 weekly episodes of 30 minutes or more duration. We then determined the increase in the proportion of ATSM patients who achieved these guidelines, relative to usual care; and using the costs of ATSM discussed above (Model A and Model B), we calculated the per-patient costs associated with achieving the 10\% increase recommended by Healthy People 2010. Trial results demonstrated a $14 \%$ increase over the study period in the proportion of participants in the ATSM group who achieved minimum standards for vigorous physical activity or exercise relative to their usual care counterparts.

\section{RESULTS}

There were 112 patients in the ATSM group and 114 patients in the usual care group. Fully $90 \%$ of patients had 12-month follow-up, with no difference between arms. None of the patient characteristics assessed differed significantly between the ATSM and the usual care groups (Table 1).

On an annual basis, the per-patient start-up costs for the ATSM intervention were $\$ 394$, and the ongoing costs were $\$ 388$ (Table 2). The total cost of this intervention per patient was therefore $\$ 782$.

The ATSM intervention was associated with a gain of 0.012 QALYs relative to usual care. For Model A (both start-up and ongoing costs), using the total cost per patient and the 0.012QALY gain for ATSM relative to usual care, the cost of the intervention was $\$ 65,167$ per QALY gained (Table 3). For Model B (ongoing costs only), this value was $\$ 32,333$. In the sensitivity analysis, in which we varied the QALY value by $10 \%$, the cost-utility ratio ranged from $\$ 59,242$ (at a $10 \%$ increase in QALY)
Table 1. Baseline Characteristics of Patients

\begin{tabular}{|c|c|c|c|}
\hline Characteristic & $\begin{array}{c}\text { ATSM } \\
(n=112)\end{array}$ & $\begin{array}{l}\text { Usual Care } \\
(\mathrm{n}=114)\end{array}$ & $P$ Value \\
\hline Age, mean (SD), years & $55.9(12.7)$ & $55.8(11.8)$ & .9 \\
\hline Women, \% & 58.0 & 55.3 & .4 \\
\hline \multicolumn{4}{|l|}{ Ethnic group, \% } \\
\hline Asian & 26.8 & 21.9 & \multirow[t]{5}{*}{.5} \\
\hline African American & 14.3 & 23.7 & \\
\hline Hispanic white & 46.4 & 48.3 & \\
\hline Non-Hispanic white & 9.8 & 5.3 & \\
\hline Other/unknown & 2.7 & 0.9 & \\
\hline \multicolumn{4}{|l|}{ Language, \% } \\
\hline English & 46.4 & 44.7 & \multirow[t]{3}{*}{1.0} \\
\hline Spanish & 42.0 & 43.9 & \\
\hline Cantonese & 11.6 & 11.4 & \\
\hline \multicolumn{4}{|l|}{ Health literacy, \% ${ }^{\mathrm{a}}$} \\
\hline Inadequate & 43.9 & 54.0 & \multirow[t]{3}{*}{.1} \\
\hline Marginal & 7.1 & 14.0 & \\
\hline Adequate & 49.0 & 32.0 & \\
\hline \multicolumn{4}{|l|}{ Education } \\
\hline Some high school & 51.8 & 55.3 & \multirow[t]{3}{*}{.6} \\
\hline High school graduate/GED & 14.3 & 19.3 & \\
\hline Some college & 33.9 & 25.4 & \\
\hline \multicolumn{4}{|l|}{ Insurance, \% } \\
\hline Medi-Cal & 20.5 & 16.7 & \multirow[t]{4}{*}{.9} \\
\hline Medicare & 19.6 & 21.9 & \\
\hline Uninsured & 50.0 & 54.4 & \\
\hline Other & 9.8 & 7.0 & \\
\hline \multicolumn{4}{|l|}{ Annual income, \% } \\
\hline$<\$ 5,000$ & 26.9 & 27.3 & \multirow[t]{5}{*}{.4} \\
\hline$\$ 5,000-\$ 10,000$ & 31.5 & 30.3 & \\
\hline$\$ 10,000-\$ 20,000$ & 18.0 & 29.3 & \\
\hline$\$ 20,000-\$ 30,000$ & 14.6 & 7.1 & \\
\hline$>\$ 30,000$ & 9.0 & 6.0 & \\
\hline Diabetes duration, mean (SD), years & $9.1(7.3)$ & $10.4(8.1)$ & .3 \\
\hline Diabetic educator visit year prior, $\%$ & 58.0 & 53.5 & .4 \\
\hline Nutritionist visit year prior, \% & 34.8 & 37.7 & .7 \\
\hline \multicolumn{4}{|l|}{ Diabetes treatment regimen, $\%$} \\
\hline Diet only & 0.0 & 2.7 & \multirow[t]{4}{*}{$.8^{\mathrm{b}}$} \\
\hline Oral agents only & 63.4 & 59.8 & \\
\hline Insulin only & 10.7 & 9.8 & \\
\hline Insulin and oral agents & 25.9 & 27.7 & \\
\hline Poor or fair health, $\%$ & 74.1 & 78.1 & .8 \\
\hline $\mathrm{HbA}_{1 c}$, mean $(\mathrm{SD}), \%$ & $9.3(1.8)$ & $9.8(2.0)$ & .2 \\
\hline \multicolumn{4}{|l|}{ Blood pressure, mean (SD), mm Hg } \\
\hline Systolic & $137.8(21.5)$ & $138.7(20.7)$ & .1 \\
\hline Diastolic & $75.7(12.1)$ & $77.8(11.2)$ & .2 \\
\hline BMI, mean (SD), kg/m² & $30.3(6.7)$ & $32.3(13.5)$ & .3 \\
\hline \multicolumn{4}{|c|}{$\begin{array}{l}\text { ATSM = Automated telephone self-management support; } \mathrm{BMI}=\text { body mass index; } \mathrm{GED}=\text { general } \\
\text { equivalency diploma; } \mathrm{HbA}_{1 \mathrm{C}}=\text { hemoglobin } \mathrm{A}_{1 \mathrm{c}} \text {. }\end{array}$} \\
\hline \multicolumn{4}{|c|}{$\begin{array}{l}\text { a Health literacy based on scores on the Short Test of Functional Health Literacy in Adults (s-TOF- } \\
\text { HLA), except for Cantonese patients }(n=39) \text {, for whom these scores were not obtained. Health } \\
\text { literacy was defined as inadequate }(0-16) \text {, marginal }(17-22) \text {, or adequate }(23-36) \text {. } \\
\text { b Fisher exact test. }\end{array}$} \\
\hline
\end{tabular}




\begin{tabular}{|lcc|}
\hline \multicolumn{2}{|l|}{ Table 2. Annual Costs of the ATSM Intervention } & \\
\hline $\begin{array}{l}\text { Cost } \\
\text { Category }\end{array}$ & Brief Description & $\begin{array}{c}\text { Cost per } \\
\text { Patient, \$ }\end{array}$ \\
\hline Start-up & $\begin{array}{l}\text { Nurse care management for } 112 \text { patients for } 9 \text { months, } \\
\text { setup of ATSM system in } 3 \text { languages }\end{array}$ & 394 \\
Ongoing & $\begin{array}{l}\text { Nurse care management for } 112 \text { patients for } 9 \text { months, } \\
\text { research assistant recruitment/follow-up, outgoing } \\
\text { calls, monthly charges } \\
\text { Both of the above }\end{array}$ & 388 \\
\hline Total & 782 \\
\hline ATSM = Automated telephone self-management support. & \\
\hline
\end{tabular}

Table 3. Annual Per-Patient Cost-Utility Ratios Associated With ATSM Relative to Usual Care

\begin{tabular}{|c|c|c|}
\hline \multirow[b]{2}{*}{ Model } & \multicolumn{2}{|c|}{ Cost-Utility Ratio, \$ per QALY Gained ${ }^{a}$} \\
\hline & Analysis & Sensitivity Analysis ${ }^{b}$ \\
\hline $\begin{array}{l}\text { Model A } \\
\quad \text { (start-up + ongoing costs) }\end{array}$ & 65,167 & $\begin{array}{l}\text { With } 10 \% \text { decrease in QALY gain: } 72,407 \\
\text { With } 10 \% \text { increase in QALY gain: } 59,242\end{array}$ \\
\hline $\begin{array}{l}\text { Model B } \\
\text { (ongoing costs only) }\end{array}$ & 32,333 & $\begin{array}{l}\text { With } 10 \% \text { decrease in QALY gain: } 35,926 \\
\text { With } 10 \% \text { increase in QALY gain: } 29,402\end{array}$ \\
\hline \multicolumn{3}{|c|}{$\begin{array}{l}\text { Notes: Cost savings were not evaluated; QALYs were estimated from scores on the } 12 \text {-Item Short Form } \\
\text { Health Survey. }\end{array}$} \\
\hline \multicolumn{3}{|c|}{$\begin{array}{l}\text { a This ratio was calculated as (cost of ATSM)/(QALY for ATSM-QALY for usual care). } \\
\text { b This analysis tested a } 10 \% \text { variation in the estimated QALY gain of } 0.012 \text { associated with ATSM in botl } \\
\text { directions: a } 10 \% \text { decrease to } 0.0108 \text { and a } 10 \% \text { increase to } 0.0132 \text {. }\end{array}$} \\
\hline
\end{tabular}

control (eg, \$35,300 per QALY gained $)^{8}$; diabetes case management $(\$ 44,941 \text { per QALY gained })^{30}$; and other commonly funded interventions that also use a health system/ program perspective. ${ }^{31,32}$ A recent report compared algorithms for cost-utility analyses based on the SF-12 using data from studies conducted in several countries. ${ }^{24}$ This report indicates that the method of Brazier and Roberts ${ }^{23}$ that we used for converting the SF-12 values has a strong methodologic basis but tends to generate relatively higher cost-utility ratios than some other algorithms, suggesting that results derived with this method may be conservative. It is encouraging that we also observed associated public health-related gains regarding exercise with ATSM, particularly in this relatively young population (mean age, 56 years), especially given recent reports indicating that aerobic training, resistance training, or both improve glycemic control

to $\$ 72,407$ (at a $10 \%$ decrease in QALY) in Model $\mathrm{A}$, and from $\$ 29,402$ (at a $10 \%$ increase in QALY) to $\$ 35,926$ (at a $10 \%$ decrease in QALY) in Model B.

Using the total per-patient ATSM cost of $\$ 782$ (start-up plus ongoing costs), the public health objective of a $10 \%$ increase in the proportion of patients achieving moderate or vigorous physical activity or exercise standards was accomplished at a cost of $\$ 558$ per patient. Using ongoing costs alone, that cost was \$277 per patient.

\section{DISCUSSION}

We are not aware of any other study that has examined the cost-effectiveness of a diabetes self-management support intervention that uses health communication technology to reach and engage a vulnerable population. We report a spectrum of cost-utility values for ATSM ranging from $\$ 65,167$ per QALY gained when including all program costs to $\$ 32,333$ per QALY gained when including only ongoing costs. Although there is no universally accepted threshold of a cost per QALY to determine whether an intervention should be adopted, ${ }^{22,24}$ these values fall well within the range reported for accepted diabetes interventions related to medication intensification, such as cholesterol control (eg, \$63,200 per QALY gained) and intensive glucose among patients with diabetes. ${ }^{33}$

It is important to note that the costs of ATSM incurred in the context of a randomized trial do not reflect full-scale implementation costs, which would lead to lower per-patient costs than reported here. Notably, in the trial, the fixed monthly maintenance service fee was distributed across a relatively small number of patients (about 100), whereas with fullscale implementation, this cost would be distributed across a much larger patient population. For example, we found a per-patient cost of $\$ 782$ for the combined start-up and ongoing implementation costs of ATSM with nurse care management. If these costs were distributed across the eligible diabetic patients in the clinic system from whom the trial sample was drawn $(>2,200 \text { patients })^{13}$ and estimated for ongoing costs only, the annual per-patient cost drops to slightly more than $\$ 300$ per patient. This amount translates into a roughly $25 \%$ decrease in the ongoing costs we estimated for the 112 ATSM patients. Currently, an initiative in the San Francisco County Medicaid health plan is enrolling hundreds of eligible members with diabetes in an ATSM program, and the per-patient costs are anticipated to be considerably lower than those in the IDEALL trial.

The estimated gain of 0.012 QALY with ATSM relative to usual care falls above the threshold for 
minimally important differences recently described in a review of health state utility measures (0.011-0.097 QALY). ${ }^{34}$ Interpreting the value of such a gain relative to its cost is difficult ; future studies should also model longer-term cost-effectiveness of increases in physical activity and improvements in functional status indicators among patients with diabetes.

Our study has several limitations. First, our calculation of the cost of ATSM relative to usual care included all quantifiable program costs, but did not include other costs related to health care use ; however, because health care use did not differ between the 2 trial arms, we believe these costs are likely to cancel each other out. Second, we did not have detailed data for analyses using a societal perspective, such as caretaker costs or work productivity. Because the IDEALL trial was designed as a "practical clinical trial,"17 we used the perspective of the publicly funded health systems that would be considering implementing similar programs as the most practical and relevant first step for providing information for decisions at the local level. Because our trial also found a significant reduction in days spent in bed because of illness, ${ }^{12}$ however, we believe an analysis that included a societal perspective likely would have yielded considerable cost-effectiveness due to savings related to avoided caretaker costs and to greater work productivity. Third, although we used an established method to convert SF-12 responses to QALYs, it is unknown whether conventionally calculated QALY utility scores among our ethnically and linguistically diverse sample would have differed from the derived QALYs that we used. Fourth, our main outcome measures were obtained via patient report, and although the SF-12 has been shown to be a valid and reliable indicator of functional status and a robust predictor of functional decline, these measures may have been subject to recall or social desirability bias. That such gains in patient-reported outcomes were not observed in the other intervention arm (group medical visits) makes these forms of bias much less likely in our analysis. Finally, although this trial is one of the first to involve socioeconomically vulnerable patients in a safety net system, the population and the setting may limit the generalizability of our findings.

We believe our cost findings are particularly relevant in the current environment in which health communication programs can harness diabetes registry data to implement population-level interventions for chronic care, ${ }^{35}$ and in light of increasing demand for information on the costs and benefits of new health care technologies in primary care settings. ${ }^{36}$ The association of ATSM with meaningful QALY improvements related to functional status and the achievement of public health objectives at modest cost suggest there may be benefits associated with widespread implementation and dissemination of ATSM-based programs in reducing diabetes-related health disparities among vulnerable populations.

To read or post commentaries in response to this article, see it online at http://www.annfammed.org/cgi/content/full/6/6/512.

Key words: Diabetes; vulnerable populations; self-management support; health information technology; cost-effectiveness; disease management; exercise; practice-based research

Submitted October 29, 2007; submitted, revised, March 5, 2008; accepted April 1, 2008.

Funding support: This study was supported by the Commonwealth Fund, AHRQ grants R21 HS014864 and R18 HS17261-01, the San Francisco Department of Public Health, and the California Healthcare Foundation. Dr Schillinger was also supported by NIH award K-23 RR16539. Electronic data and resources of the UCSF-SFGH General Clinical Research Center were made available through NIH grant UL1 RR024131.

Disclaimer: The views presented here are those of the authors and should not be attributed to the Commonwealth Fund or its directors, officers, or staff.

\section{References}

1. Hoffman C, Rice D, Sung HY. Persons with chronic conditions. Their prevalence and costs. JAMA. 1996;276(18):1473-1479.

2. Narayan K, Zhang P, Kanaya A, et al. Disease Control Priorities in Developing Countries. 2nd ed. New York, NY: Oxford University Press; 2006:591-604.

3. Krein SL, Funnell MM, Piette JD. Economics of diabetes mellitus. Nurs Clin North Am. 2006;41(4):499-511, v-vi.

4. Krein SL, Heisler M, Piette JD, Makki F, Kerr EA. The effect of chronic pain on diabetes patients' self-management. Diabetes Care. 2005;28(1):65-70.

5. McCulloch DK, Price MJD, Hindmarsh M, Wagner EH. Improvement in diabetes care using an integrated population-based approach in a primary care setting. Dis Manage. 2000;3(2):75-82.

6. Ettaro L, Songer TJ, Zhang P, Engelgau MM. Cost-of-illness studies in diabetes mellitus. Pharmacoeconomics. 2004;22(3):149-164.

7. Hogan P, Dall T, Nikolov P. Economic costs of diabetes in the US in 2002. Diabetes Care. 2003;26(3):917-932.

8. Zhang P, Engelgau MM, Norris SL, Gregg EW, Narayan KM. Application of economic analysis to diabetes and diabetes care. Ann Intern Med. 2004;140(11):972-977.

9. Klonoff DC, Schwartz DM. An economic analysis of interventions for diabetes. Diabetes Care. 2000;23(3):390-404.

10. Glasziou P, Alexander J, Beller E, Clarke P, Group AC. Which healthrelated quality of life score? A comparison of alternative utility measures in patients with type 2 diabetes in the ADVANCE trial. Health Qual Life Outcomes. 2007;5(21):1-11.

11. Guilkey DK, Hutchinson P, Lance P. Cost-effectiveness analysis for health communication programs. J Health Commun. 2006;11(Suppl 2):47-67.

12. Schillinger D, Handley M, Wang F, Hammer $H$. Effects of self-management support on structure, process, and outcomes among vulnerable patients with diabetes: a 3-arm randomized trial [abstract]. Presented at the 30th Society of General Internal Medicine Annual Meeting, Totonto, Canada, April 25-28, 2007. 
13. Schillinger D, Hammer $H$, Wang $F$, et al. Seeing in 3-D: examining the reach of diabetes self-management support strategies in a public healthcare system. Health Educ Behav. 2007 May 18 [Epub ahead of print].

14. US Department of Health and Human Services. Healthy People 2010. Understanding and Improving Health. 2nd ed. Washington, DC: US Government Printing Office; November 2000.

15. American Diabetes Association. Standards of medical care in diabetes 2007. Diabetes Care. 2007;30(Suppl 1):S4-S41.

16. Hogan P, Dall T, Nikolov P; American Diabetes Association. Economic costs of diabetes in the US in 2002. Diabetes Care. 2003;26(3):917-932.

17. Handley MA, Hammer $H$, Schillinger D. Navigating the terrain between research and practice: a Collaborative Research Network (CRN) case study in diabetes research. J Am Board Fam Med. 2006;19(1):85-92.

18. McCollum M, Ellis S, Regensteiner J, Zhang W, Sullivan P. Minor depression and health status among US adults with diabetes mellitus. Am J Manag Care. 2007;13(2):65-72.

19. Piette JD. Interactive voice response systems in the diagnosis and management of chronic disease. Am J Manag Care. 2000;6(7):817-827.

20. Piette JD, Weinberger M, McPhee SJ, Mah CA, Kraemer FB, Crapo LM. Do automated calls with nurse follow-up improve self-care and glycemic control among vulnerable patients with diabetes? Am J Med. 2000;108(1):20-27.

21. Goldman LE, Handley M, Rundall TG, Schillinger D. Current and future directions in Medi-Cal chronic disease care management: a view from the top. Am J Manag Care. 2007;13(5):263-268

22. Gold M, Siegal J, Russell L, Weinstein M. Cost-Effectivenes in Health and Medicine. The Report on the Panel on Cost-Effectiveness in Health in Medicine. New York, NY: Oxford University Press; 1996.

23. Brazier JE, Roberts J. The estimation of a preference-based measure of health from the SF-12. Med Care. 2004;42(9):851-859.

24. Pickard AS, Wang Z, Walton SM, Lee TA. Are decisions using costutility analyses robust to choice of SF-36/SF-12 preference-based algorithm? Health Qual Life Outcomes. 2005;4(3):11.
25. Wolff N, Helminiak TW, Tebes JK. Getting the cost right in costeffectiveness analyses. Am J Psychiatry. 1997;154(6):736-743.

26. Hutchinson P, Wheeler J. The cost-effectiveness of health communication programs: what do we know? J Health Commun. 2006;11(Suppl 2):7-45.

27. Crowe BL. Cost-effectiveness analysis of telemedicine. J Telemed Telecare. 1998;4(Suppl 1):14-17.

28. Shumway M, Boccellari A, O'Brien K, Okin R. Cost-effectiveness of clinical case management for ED frequent users: results of a randomized trial. Am J Emerg Med. 2008;26(2):155-164.

29. Muennig P. Designing and Conducting Cost-Effectiveness Analysis in Medicine and Health Care. San Francisco, CA: Jossey-Bass; 2002:298.

30. Gilmer T, Roze S, Valentine W, et al. Cost-effectiveness of diabetes case management for low income populations. Health Serv Res. 2007:45(5):1943-1959.

31. The CDC Diabetes Cost-effectiveness Group. Cost-effectiveness of intensive glycemic control, intensified hypertension control, and serum cholesterol level reduction for type 2 diabetes. JAMA. 2002;287(19):2542-2551.

32. Cohen JT, Neumann PJ, Weinstein MC. Does preventive care save money? Health economics and the presidential candidates. $N$ Engl J Med. 2008;358(7):661-665.

33. Sigal RJ, Kenny GP, Boule NG, et al. Effects of aerobic training, resistance training, or both on glycemic control in type 2 diabetes: a randomized trial. Ann Intern Med. 2007;147(6):357-369.

34. Walters SJ, Brazier JE. Comparison of the minimally important difference for two health state utility measures: EQ-5D and SF-6D. Qual Life Res. 2005;14(6):1523-1532.

35. Gill TM, Allore H, Guo Z. Restricted activity and functional decline among community-living older persons. Arch Intern Med. 2003;163(11):1317-1322.

36. Selby JV, Scanlon D, Lafata JE, Villagra V, Beich J, Salber PR. Determining the value of disease management programs. Jt Comm J Qual Saf. 2003;29(9):491-499. 